\title{
Characteristics Analysis of Aging Composite Insulators
}

\author{
Yue Cao ${ }^{1, \mathrm{a}}$, Zhibo Zhang ${ }^{1, \mathrm{~b}}$, Xuan Chen ${ }^{1, \mathrm{c}}$, Ming Chi $^{1, \mathrm{~d}},{ }^{2}$ Chuanmin Chen ${ }^{1, \mathrm{e}}$, Ke \\ $\mathrm{Du}^{2, \mathrm{f}}$ and Jing Zhang ${ }^{1, \mathrm{~g}}$ \\ ${ }^{1}$ School of Environmental Science \& Engineering, North China Electric Power University, Baoding \\ 071003, China; \\ ${ }^{2}$ Henan Epri Electric Power Technology Co.,Ltd, Zhengzhou 450052, China. \\ a cyue1520@126.com, ${ }^{b}$ 18233138073@163.com, ${ }^{c}$ ccbabyon@sina.cn, ${ }^{d} 15633210521 @ 163 . c o m$, \\ e106619568@qq.com, ${ }^{\mathrm{f}}$ duke@163.com, ${ }^{\mathrm{g}}$ ncepu_zhangjing@163.com
}

Keywords: composite insulator, aging, infrared spectrum, thermogravimetric analysis

\begin{abstract}
Composite insulators have been widely used for transmission line, which have been noted for the aging problem with the increase of the installed number and service time. Characteristics analysis of aging composite insulators were analyzed using attenuated total reflect ion infrared spectroscopy (ATR-FTIR) and thermogravimetric analysis (TGA) respectively. Results showed that the aging rate of composite insulators were increased by higher voltage and longer operation period, and molecular fracture was the main performance of aging. It was suggested that sheds materials for composite insulators of various aging degree shows good thermostability without significant difference.
\end{abstract}

\section{Introduction}

Composite insulators have been used in China's power system from the early 1980s. Though started relatively late, China's power industry has already made developments of the composite insulators on the basis of domestic and international experience[1-3]. After 30 years' development, composite insulators have been used in transmission line over 20a in some areas of China. On the whole, good performance and high reliability of composite insulators were shown in the long-term operation, despite of some incidents and anomalies. A large number of composite insulators will be decommissioned from the power transmission lines in the next few years according to their designed service life. The aging of composite insulators will be a great issue to power transmission industry[4-6].

In this paper, ATR-FTIR and TGA were used to analyze the characteristics of aging composite insulators.

\section{Experimental}

In ATR-FTIR experiment, the sheds were obtained from different positions of different composite insulators types. The functional groups and polymer main chains of the insulator shed materials were studied during the aging process [7]. The thermal stability of composite insulators on different aging degree were analyzed by TGA. The aging characteristics of composite insulators were indicated in this study [8].

\section{Results and discussion}

Insulation materials for composite insulators are composed of high temperature vulcanized (HTV) silicone rubber. The main component of the raw rubber is poly dimethyl siloxane (PDMS). The structure of PDMS was shown in Fig. 1. The closely spaced non-polar methyl groups around silicone main chain oriented toward the surface, which shield the strong polarity effect of Si-O bond. Thus silicone rubber showed excellent hydrophobicity. 


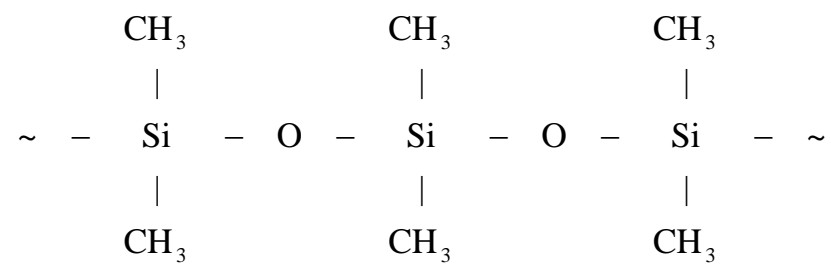

Fig. 1 Structure of PDMS

\subsection{ATR-FTIR measurement of composite insulators at different voltage levels.}

The wear composite insulators operated for 7 years under similar operating conditions in different voltages were used in this study. All the insulators were from the same manufacturer. The result was shown in Fig. 2.

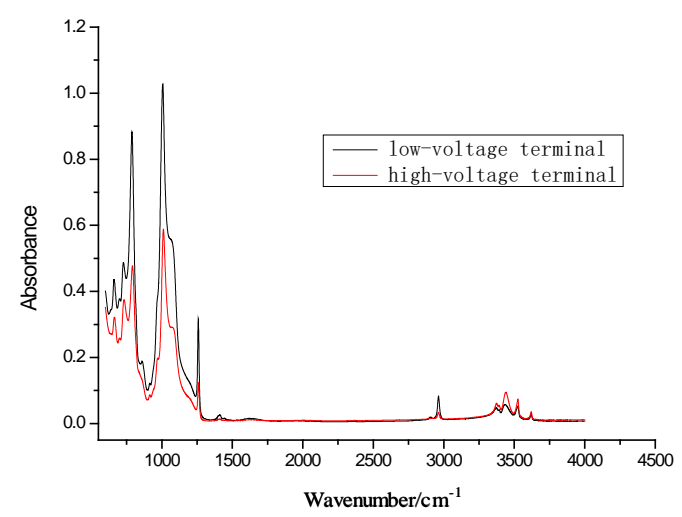

(a)ATR-FTIR spectra of $110 \mathrm{kV}$ insulators on high-voltage terminal and low-voltage terminal

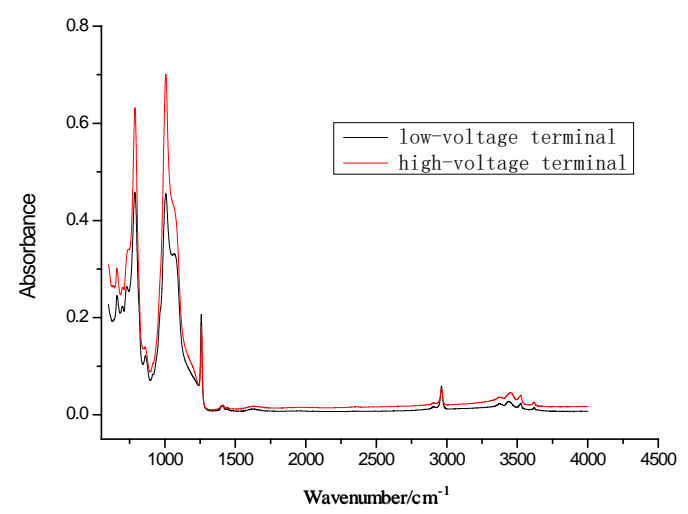

(b)ATR-FTIR spectra of $220 \mathrm{kV}$ insulators on high-voltage terminal and low-voltage terminal

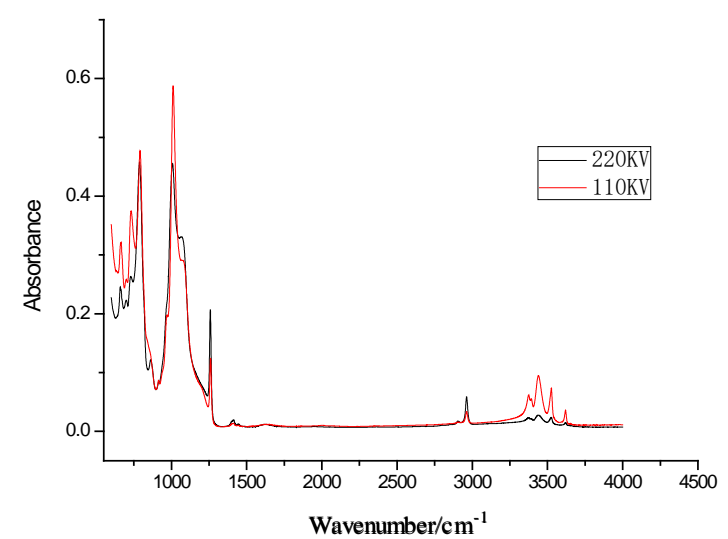

(c) ATR-FTIR spectra of $110 \mathrm{kV}$ and $220 \mathrm{kV}$ insulators on high-voltage terminal

Fig. 2 FTIR spectra of external surface of composite insulators at different voltages 
As shown in Fig. 2, compared with the intermediate umbrella skirt, the spectral absorption peak area which corresponds to $\mathrm{Si}-\mathrm{CH}_{3}$ and Si-O-Si groups in the infrared spectrum of insulators on the high-voltage terminal was significantly smaller. This result indicated that umbrella skirt on high-voltage terminal aged more seriously than that on low-voltage terminal. Umbrella skirt on the high-voltage terminal was close to transmission lines and its surrounding electric field intensity was higher than those of intermediate umbrella skirt.

\subsection{ATR-FTIR measurement of composite insulators with different operating conditions.}

Composite insulators with similar operating life and different operating conditions were analyzed by ATR-FTIR. The impact of running environment to the aging of insulators was studied in the experiment. The basic information of the four sets of $110 \mathrm{kV}$ composite insulators were listed in Table 1.

Table 1 Basic information of composite insulators

\begin{tabular}{|c|c|c|c|c|}
\hline Number & Operating year & Manufacturer & Region & Environment \\
\hline 110kV-C-8a & 8 & $\mathrm{C}$ & $\begin{array}{l}\text { Hebei } \\
\text { Province }\end{array}$ & Coastal area \\
\hline 110kV-C-8a & 8 & $\mathrm{C}$ & $\begin{array}{l}\text { Zhejiang } \\
\text { Province }\end{array}$ & Wayside \\
\hline 110kV-C-8a & 8 & $\mathrm{C}$ & $\begin{array}{l}\text { Hubei } \\
\text { Province }\end{array}$ & Flat; Xiangcheng district,Xiangfan city \\
\hline 110kV-E-11a & 11 & $\mathrm{E}$ & $\begin{array}{l}\text { Sichuan } \\
\text { Province }\end{array}$ & Peri-urban area; III polluted area \\
\hline 110kV-E-11a & 11 & $\mathrm{E}$ & $\begin{array}{l}\text { Hebei } \\
\text { Province }\end{array}$ & Plain \\
\hline
\end{tabular}

The result of ATR FTIR spectra of $110 \mathrm{kV}$ composite insulators from $\mathrm{C}$ and $\mathrm{E}$ manufacturers were shown in Fig. 3 and Fig. 4 respectively.

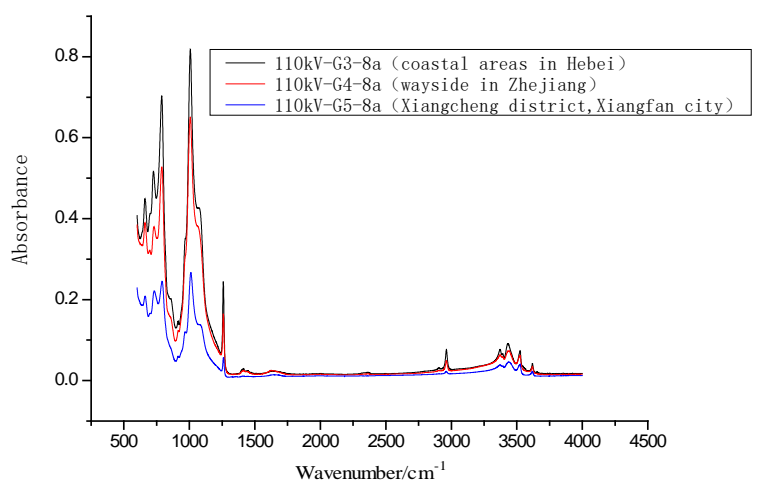

Fig. 3 ATR FT-IR spectra of composite insulators from C manufacturer operated for 8 years under different conditions

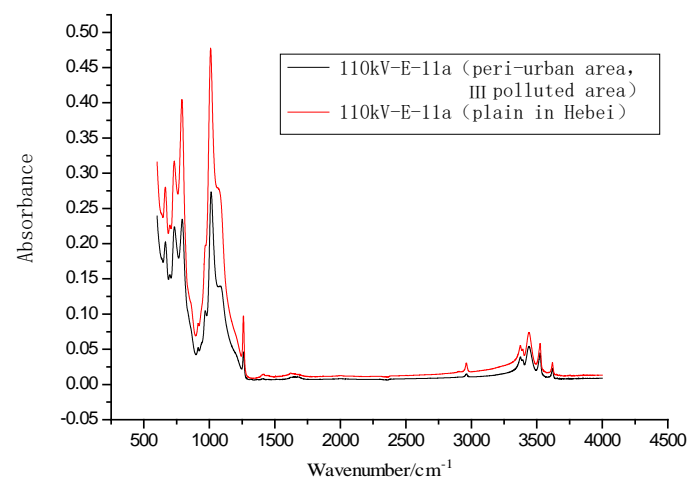

Fig. 4 ATR FT-IR spectra of composite insulators from E manufacturer operated for 11 years under different conditions 
As shown in Fig. 3, although produced by the same manufacturer, ATR FT-IR spectra of composite insulators operated for 8 years under different circumstances can vary a lot. Insulators operating in coastal areas of Cangzhou aged more slightly, then the wayside of ZheJiang Province. Insulators in Xiangcheng District aged most severely. Fig. 4 showed that the insulators operated in peri-urban areas of Sichuan aged more seriously than Hebei. This illustrated that the aging degree of the insulators is deeper in the crowed area due to high amount of anthropogenic contaminations.

\subsection{TGA measurement.}

$12 \mathrm{mg}$ composite insulator sample was heated up to $800^{\circ} \mathrm{C}$ at a heating rate of $20^{\circ} \mathrm{C} / \mathrm{min}$ under synthesis air flow, the gas flow rate is $20 \mathrm{ml} / \mathrm{min}$. The map included two parts: thermal gravity(TG) curves and differential thermal gravity(DTG) curves. The weight loss of samples changing with the temperature was revealed in TG curves, and the instantaneous rate of thermal cracking reaction of the samples was shown in DTG curves.

Composite insulators from the same manufacturer in different operating life were analyzed by TGA. The samples were respectively new composite insulators $\left(1^{\#}\right)$, insulators operated for 5 years $\left(2^{\#}\right)$ and insulators operated for 8 years $\left(3^{\#}\right)$. the TGA and DTG profiles was shown in Fig. 5-7.
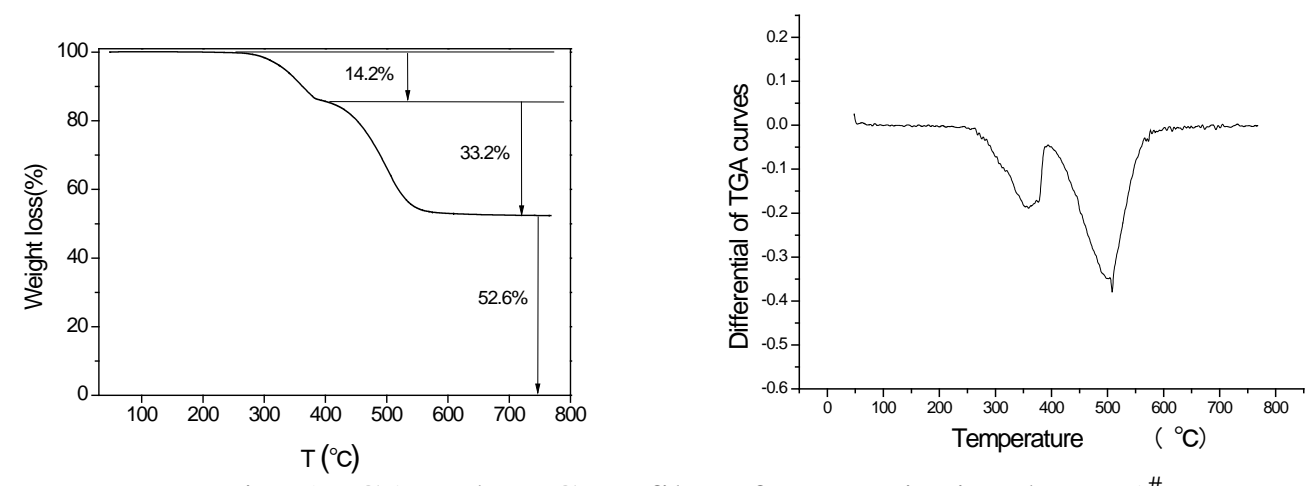

Fig. 5 TGA and DTG profiles of composite insulators $1^{\#}$
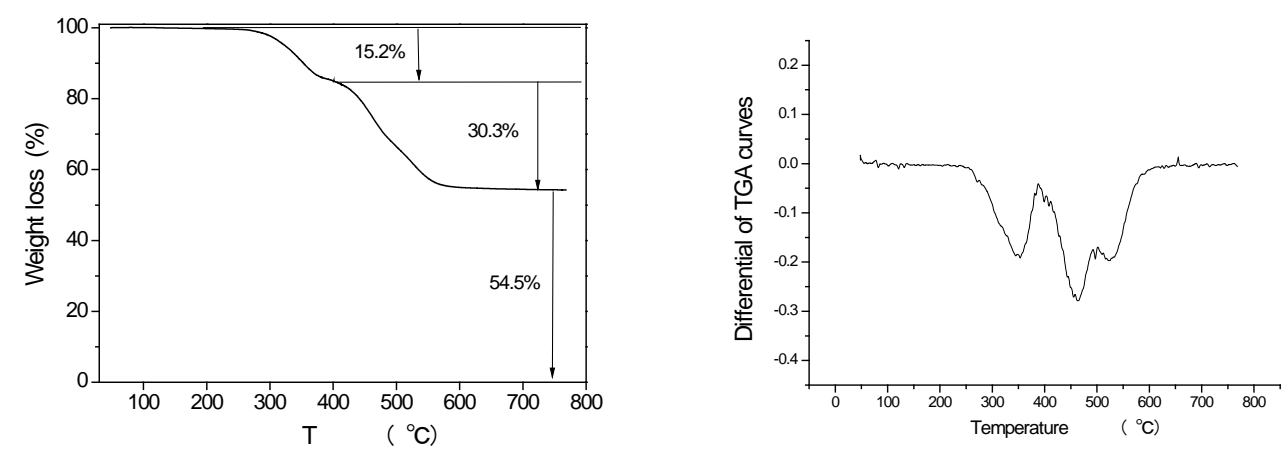

Fig. 6 TGA and DTG profiles of composite insulators $2^{\#}$
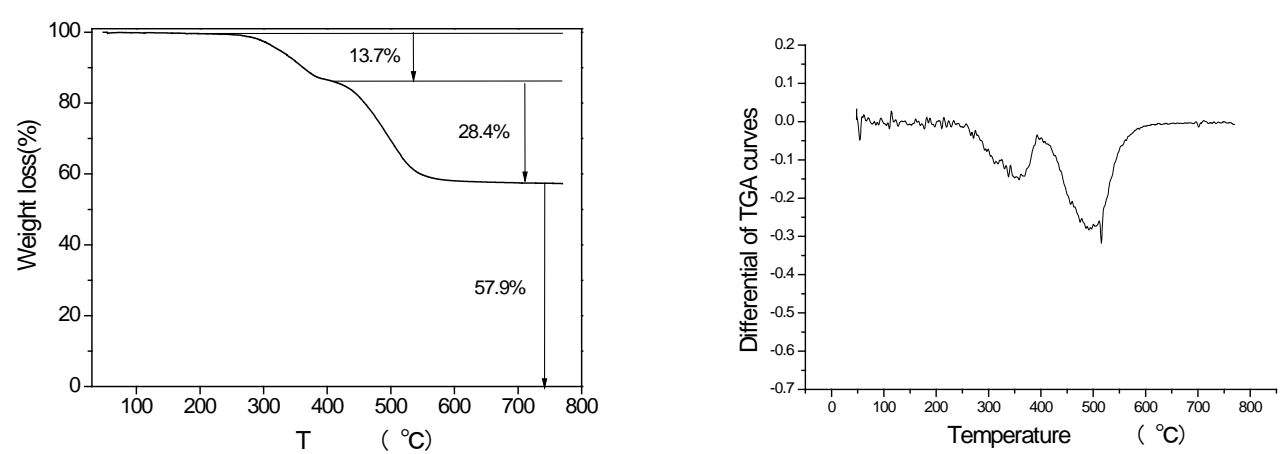

Fig. 7 TGA and DTG profiles of composite insulators $3^{\#}$

The result showed that $5 \%$ weight loss temperature decreased slightly with the increase of operating year. It can be illustrated that the composite insulators had a good thermostability at room temperature and qualitative change wouldn't occur for a long time laying aside since the three 
temperatures were all between $320-335^{\circ} \mathrm{C}$. The temperatures were listed in Table 2 .

Table 2 The $5 \%$ weight loss temperature of samples

\begin{tabular}{cccc}
\hline & $1^{\#}$ & $2^{\#}$ & $3^{\#}$ \\
\hline $\begin{array}{c}5 \% \text { weight loss } \\
\text { temperature }\end{array}$ & $333.6^{\circ} \mathrm{C}$ & $323.7^{\circ} \mathrm{C}$ & $324.2^{\circ} \mathrm{C}$ \\
\hline
\end{tabular}

\section{Conclusion}

With the increase of mounting operating time, the umbrella skirt coat of composite insulators occurred various degrees of aging.

The result showed that spectral absorption peak area corresponds to the high-voltage terminal was significantly smaller than low-voltage terminal, indicating that the aging degree of high-voltage terminal on the same umbrella skirt is apparently higher. Besides, composition insulators at higher voltage level aged more seriously.

ATR FT-IR spectra of composite insulators under different circumstances could vary a lot, despite of the same manufacturer. Composite insulators aged more seriously in cities and industrial regions with frequent human activities.

It can be illustrated that new composition insulators share the same thermostability with the aged. The $5 \%$ weight loss temperatures were between $320^{\circ} \mathrm{C}-335^{\circ} \mathrm{C}$, which shows that composite insulators had a good thermostability. Qualitative change did not occur at room temperature basically.

\section{References}

[1]. J.B. Fan, Y. Yin, J.X. Zhang, et al. Evaluation Methods for Operational Status of Composite Insulators. Power System Technology. Vol. 30 (2006) No. 12, p. 24-28.

[2]. T. Wang, G.Y. Wu, R. Zhang, et al. State Evaluation for the Composite Insulators' Status in Operational Mode and Its Experimental Study. Power System Technology. Vol. 32 (2008) Supplement 1, p. 146-149.

[3]. L.Y. Chen. Application of Composite Insulator in Transmission Line. Science \& Technology Association Forum. (2011) No. 1, p. 17-18.

[4]. F.Z. Zhang, L. Song, Y.P. Tu, et al. Analysis of Operating Performance for the $500 \mathrm{kV}$ Composite Insulator. High Voltage Engineering. Vol. 38 (2012) No. 10, p. 2536-2537.

[5]. D. Yan, M. Lu, K. Zhang, et al. Assessment on Operation Characteristics of Composite Insulators Used for Transmission Line in Henan Province Power Network. Power System Technology. Vol. 30 (2006) No. 12, p. 79-82.

[6]. T.J. Yang. Analysis on Composite Insulators Operation for LiaoNing Power Network. China Electric Power: Technology Edition. (2012) No. 11, p. 160-165.

[7]. Y.P. Tu, C.H. Chen, Y.L. Qiao, et al. Aging Characteristics of Shed Materials of Silicone Rubber Compostite Insulators in Service. High Voltage Engineering .Vol. 38 (2012) No. 10, p. 2522-2524.

[8]. H.W. Cao, D. Yan, J.H. Han, H. Ren, M. Lu, Z.B. Lv, et al. Investigation and Corroboration of a Novel Method to Estimate the Hydrophobicity of Composite Insulators. IEEE Trans. Dielectr. Electr. Insul. Vol. 19 (2012) No. 6, p. 2029-2036. 